\title{
The Role of Strategic and Value Chain Flexibility in Achieving Sustainability Performance: An Empirical Analysis Using Conventional and Consistent PLS
}

\author{
Completed Research Paper
}

\author{
Carsten Gelhard \\ University of Twente \\ c.gelhard@utwente.nl
}

\author{
Stephan von Delft \\ University of Amsterdam \\ s.vondelft@uvan.nl
}

\begin{abstract}
We contribute to the clarification of the link between dynamic and operational capabilities by examining how strategic flexibility and value chain flexibility translate into superior sustainability performance. Using survey data of chemical firms in Germany, our structural equation model shows that value chain flexibility fully mediates the relationship between strategic flexibility and sustainability performance. Further, we contribute to the ongoing research on the partial least squares (PLS) approach to structural equation modeling by estimating the proposed research model with both conventional and consistent PLS (PLSc) and outlining a guideline for evaluating and reporting PLSc-related findings.
\end{abstract}

Keywords: Strategic Flexibility, Value Chain Flexibility, Sustainability Performance, Consistent PLS, Structural Equation Modeling

\section{Introduction}

How companies can reconcile economic, social, and environmental performance has been actively debated in the management literature (Hart, 1995; Kolk and Pinske, 2005) While firms aim to create a differentiation-based competitive advantage by integrating sustainability into their strategy, there is a disconnection between these thoughts and action: As recently shown, only $40 \%$ of executives report that their organizations address sustainability issues and even more surprising only $10 \%$ state that their business fully tackles these issues (Kiron et al., 2013). Scholars conclude that companies should do more in order to actually transfer their direction towards sustainability issues into true business solutions (Berns et al., 2009).

One particular challenge in becoming more sustainable is to create flexibility in exploiting and controlling resources in the pursuit of alternative strategic actions. Companies that are able to flexibly allocate their resources are in a better position to deal with environmental changes, design more sustainable offerings (e.g., products that are based on renewable inputs), invest in manufacturing technologies that demand less energy or avoid toxic by-products, commit resources to new business opportunities, or reverse unproductive resource deployment (Bock et al., 2012; Zhou and $\mathrm{Wu}, 2010)$. Indeed, flexibility in resource allocation may explain why some companies move faster into new niches than their competitors through initiating strategic and organizational change, e.g., developing new business models, and committing resources to implement strategic actions rapidly (Eisenhardt and Martin, 2000; Nadkarni and Narayanan, 2007).

However, although strategic flexibility is considered to be indispensable to respond to environmental changes, including the increasing demand to satisfy economic needs while simultaneously considering human welfare and ecological constraints, it remains unclear how 
this dynamic capability translates into superior sustainability performance (e.g., Nidumolu et al., 2009). Changing a firm's strategy might be ineffective without adequately adapting structures and processes at the operational level (e.g., Milgrom and Roberts, 1990). Helfat and Peteraf argue that "[d]ynamic capabilities do not directly affect output for the firm in which they reside, but indirectly contribute to the output of the firm through an impact on operational capabilities" (2003, p. 999). Hence, we argue that strategic flexibility - representing an important dynamic capability - does not directly impact sustainability performance (e.g., Eisenhardt et al., 2010; Teece et al., 1997). Since strategic flexibility rather builds, integrates, and reconfigures operational capabilities, we eventually propose value chain flexibility as an important operational capability in the pursuit of superior sustainability performance (Helfat and Peteraf, 2003; Kortmann et al., 2014; Teece et al., 1997). Value chain flexibility relates to the firm's ability to adapt its operational activities across the entire value chain, including product development, manufacturing, logistics, and spanning activities, to changing customer needs (Zhang et al., 2002).

Taken together, this study empirically examines the mediating role of value chain flexibility within the relationship of strategic flexibility and sustainability performance. Using a top-level manager dataset of chemical firms located in Germany, we contribute to the ongoing debate on the triple bottom line within the management literature by showing how superior sustainability performance results from a firm's ability to (i) flexibly allocate its resources at the strategic level and (ii) adequately adapt it structures and processes at the operational level. Furthermore, we contribute to the ongoing research on the partial least squares (PLS) approach to structural equation modeling (SEM). Following most recent literature, we estimated our proposed research model by means of consistent PLS (PLSc) as an extension to conventional PLS. While maintaining all strengths of conventional PLS, PLSc overcomes the lack of consistency and corrects for attenuation of regression path estimates. We finally examine whether the results deriving from conventional PLS and PLSc significantly differ for our proposed research model. In so doing, we borrow from the literature on PLS-SEM and outline a guideline for evaluating and reporting PLSc-related findings.

\section{Hypotheses}

\subsection{Strategic Flexibility and Value Chain Flexibility}

As business environments have become more competitive and dynamic than ever before, companies are continuously forced to adapt to environmental changes (Grewal and Tansuhaj, 2001; Young-Ybarra and Wiersema, 1999). The ability of a company to rapidly identify major changes in the competitive landscape, reallocate resources to new courses of action and reconfigure existing organizational routines that support these actions, will ultimately determine whether a company can faster create competitive advantage than its rivals (e.g., Eisenhardt, 1989; Shimizu and Hitt, 2004; Nadkarni and Narayanan, 2007). This adaptive capability is known as strategic flexibility and refers to the "ability of a firm to reallocate and reconfigure its organizational resources, processes, and strategies to deal with environmental changes" (Zhou and Wu, 2010, p. 549). Following prior literature, strategic flexibility is classified as an important dynamic capability (Eisenhardt et al., 2010; Teece et al., 1997), which represents the ability to build, integrate, and reconfigure operational capabilities (Helfat and Peteraf, 2003; Kortmann et al., 2014; Teece et al., 1997). Hence, by continuously creating and recombining resources in novel ways, dynamic capabilities have a direct impact on operational capabilities (Helfat and Peteraf, 2003; Kortmann et al., 2014). The latter involve the execution and coordination of various tasks, such as the development, manufacturing, and marketing of products and services (Helfat and Peteraf, 2003). Based on this classification of dynamic and operational capabilities, we argue that strategic flexibility is positively associated with value 
chain flexibility. Value chain flexibility represents an operational capability that ensures the flexible adaption of operational activities across the entire value chain, including product development, manufacturing, logistics, and spanning activities, to changing customer needs (Zhang et al., 2002). Strategic flexibility enables companies to redeploy assets such as productcreating resources to meet a variety of customer expectations (e.g., meeting high ecological standards while reducing product price) and supplier demands without performance loss. Through enabling response to unanticipated changes and unexpected consequences of predictable changes (Bahrami, 1992), strategic flexibility acts as an organizing principle, which enhances the coordination of product design, production and distribution, and allows firms to take operational actions, e.g., adjust production volume or respond to ad-hoc requests made by customers (Nair, 2005; Young-Ybarra and Wiersema, 1999; Zhang et al., 2003). We therefore hypothesize:

\section{H1: Strategic flexibility is positively associated with value chain flexibility.}

\subsection{Value Chain Flexibility and Sustainability Performance}

In order to effectively and efficiently respond to changing customer needs, including the increasing demand for sustainable offerings, firms are forced to re-design their operational processes and implement a flexible system of structures and processes across their value chain (e.g., Nair, 2005; Kolk and Pinske, 2005; Zhang et al., 2002; Zhang et al., 2003). Nidumolu et al., for instance, argue that operational innovations are central to building a sustainable value chain and, hence, conclude that companies need to develop the "ability to re-design operations" (2009, p. 61). Following Zhang et al., "the breadth and intensity of flexibility needed to cope with changing customer requirements [however] cannot be provided by one department or function" (2003, p. 175). In order to increase responsiveness and to eliminate bottlenecks across the value chain, flexibility in operational activities needs to be present in various activities, including product development, manufacturing, logistics, and spanning activities (Zhang et al., 2002; Zhang et al., 2003). These activities include the integration, coordination, and communication across the internal as well as external value chain (e.g., Zhang et al., 2003). Considering that the increasing demand for sustainable solutions very often implies a shift from the sole focus on end-customers toward the consideration of earlier stages of the value chain, the ability to share information with suppliers and customers is indispensable in the pursuit of superior sustainability performance. Although sustainability has been identified as an emerging global trend in almost all industries, the willingness to pay an extra price for sustainable offering still varies among customers. Hence, the successful introduction of sustainable products or services might also strongly benefit from the firm's ability to externally and internally share both standardized (e.g., information on the general function and usability of a product or service) and customized information (e.g., information on customer-specific needs associated with sustainability). Based on this discussion, we propose:

H2: Value chain flexibility is positively associated with sustainability performance.

\section{Methodology}

\subsection{Sample and Key Informant Check}

The data of the present study derive from an undertaken online survey of top-level managers of chemical firms located in Germany. The chemical industry was chosen as research context since it reflects an industry that has been successful in making business cases for sustainability (e.g., Jenck et al., 2004). For data collection, we choose an online questionnaire with closed questions. Apart from advertising our study within a practitioner-oriented magazine, we directly invited top-level managers via email to participate in our online survey. 


\subsection{Non-Response Bias}

Since the present study might be potentially threatened by non-response bias, we performed a post-hoc analysis and tested for differences between (i) early and late respondents (Armstrong and Overton, 1977; Li and Calantone, 1998) and (ii) participants that completed the survey and participants that abandoned. Both Mann-Whitney U-tests revealed no significant differences between the different groups.

\subsection{Key Information Check}

For data collection, we applied a key informant approach and solely included responses of top-level managers in the final dataset of our study. To reduce the potential risk that participants respond to questions beyond their level of responsibility, we applied the following key informant criteria: (i) involvement in strategic, innovation, and operational decision making, (ii) job title, (iii) job experience, and (iv) organizational tenure (see Appendix A).

\subsection{Measures}

Our proposed research model consists of three multi-item reflective scales. Strategic flexibility was measured using a six-item construct adapted from Zhou and $\mathrm{Wu}$ (2010). Value chain flexibility was measured using a six-item construct adapted from Nair (2005), who drew upon the conceptualization introduced by Zhang et al. (2002). Sustainability performance is a new performance measure we developed to operationalize competitive advantage that is achieved by meeting the needs of organizational stakeholders while simultaneously considering human welfare and ecological constraints (e.g., Chow and Chen, 2012; Nidumolu et al., 2009). The measurement items are outlined in Appendix B.

\subsection{Common Method Variance}

In order to test whether our findings are potentially threatened by common method bias, we included a common method variance factor that comprises all principal constructs' indicators in our structural model (Podsakoff et al., 2003, Liang et al., 2007). We compared the variance of each principal construct's indicator as explained by the common method and substantive factors. The model estimation with PLS revealed an average substantive explained variance of 0.71 and an average common method based variance of 0.01 . The resulting ratio of the average substantive explained variance to the average common method based variance is about 71:1.

\section{Analysis and Results}

Following recent research across various business disciplines, e.g. marketing, operations management, and information systems, we applied PLS-SEM. Among variancebased SEM techniques, PLS can be regarded as the most advanced approach to SEM (Dijkstra and Henseler, 2015a). PLS path modeling is to be preferred over alternative covariance-based techniques, when the primary aim of the study rather relates to causal-predictive analysis than theory testing (e.g., Hair et al., 2012; Henseler et al., Sinkovics, 2009). Compared to covariancebased techniques, PLS-SEM has minimum demands regarding sample size (Chin et al., 2003; Hair et al., 2012). Furthermore, PLS-SEM is more favorable when the proposed research model comprises a high degree of complexity (Chin and Newsted, 1999; Henseler and Chin, 2010). However, similar to other analysis techniques, PLS-SEM is not without disadvantages. The main downsides of PLS-SEM are the lack of (i) consistency and (ii) and overall goodness-offit measure (e.g., Dijkstra and Henseler, 2015b; Henseler and Sarstedt, 2013). PLS estimates are only consistent under the conditions of 'consistency at large' and, hence, demand large numbers of both observations and measurements items per construct (Dijkstra and Henseler, 2015a,b; Peng and Lai, 2012). The reason is the approximation of latent variables as linear 
combinations of their respective observed indicators within PLS-SEM (Henseler et al., 2014; Dijkstra and Henseler, 2015b). While this approach is proper to estimate composite factor models, the PLS-SEM is not consistent for common factor models (e.g., Henseler et al., 2014; Dijkstra and Henseler, 2015a,b). Considering that the PLS algorithm approximates common factors as linear composites of observed indicators (Dijkstra and Henseler, 2015a,b), prior scholars have acknowledged that "parameter estimates for paths between observed variables and latent variable proxies are biased upward in PLS (away from zero), while parameter estimates for paths between proxies are attenuated" (Gefen et al. 2011, p. vi). To overcome the lack of inconsistency, recent literature has introduced an important advancement to PLS: consistent PLS (PLSc) (Dijkstra and Henseler, 2015a,b). PLSc corrects the estimates of reflectively measured constructs deriving from the traditional iterative PLS algorithm by employing a new reliability coefficient, termed as Dijkstra-Henseler's rho (pA). Considering the advantages implied by PLSc, we employed the PLSc approach to SEM in addition to conventional PLS, using SmartPLS 3.0 (Ringle, Wende, and Becker, 2015) and Adanco 1.0 (Composite Modeling, 2014). Borrowing from the literature on PLS-SEM (e.g., Gefen et al., 2011; Hair et al., 2012; Henseler et al., 2009; Hulland, 1999; Peng and Lai, 2012), we outline a guideline for evaluating and reporting PLSc-related findings.

\subsection{Validity and Reliability}

Following prior literature (e.g., Hair et al., 2011; Hulland, 1999), we assessed the outer model by means of (i) individual item reliability, (ii) internal consistency reliability, (iii) convergent validity, and (iv) discriminant validity. Individual item reliability refers to the correlation of each indicator with its latent variable and, hence, is represented by the outer loadings within PLS/PLSc. While all items exceed the suggested threshold of 0.70 with regard to the estimation using PLS (Henseler et al., 2009; Hulland, 1999), the estimation of our proposed research model with PLSc reveals some outer loadings that are below the recommended cut-off value of 0.70 (see Table 1). The comparison between PLS and PLSc in Table 1 eventually supports prior literature (Dijkstra and Henseler, 2015a), which also shows that the estimation with conventional PLS leads to an overestimation of the absolute value of loadings.

Table 1. Individual item reliability (outer loadings)

\begin{tabular}{|c|c|c|c|c|c|c|}
\hline & \multicolumn{2}{|c|}{$\begin{array}{c}\text { Strategic } \\
\text { Flexibility }\end{array}$} & \multicolumn{2}{|c|}{$\begin{array}{c}\text { Value Chain } \\
\text { Flexibility }\end{array}$} & \multicolumn{2}{|c|}{$\begin{array}{l}\text { Sustainability } \\
\text { Performance }\end{array}$} \\
\hline & PLS & PLSc & PLS & PLSc & PLS & PLSc \\
\hline SF_1 & 0.76 & 0.58 & & & & \\
\hline SF_2 & 0.80 & 0.76 & & & & \\
\hline SF_3 & 0.74 & 0.49 & & & & \\
\hline SF_4 & 0.91 & 0.96 & & & & \\
\hline SF_5 & 0.84 & 0.90 & & & & \\
\hline VCF_1 & & & 0.75 & 0.68 & & \\
\hline VCF_2 & & & 0.78 & 0.67 & & \\
\hline VCF_3 & & & 0.84 & 0.90 & & \\
\hline VCF_4 & & & 0.90 & 0.77 & & \\
\hline VCF_5 & & & 0.84 & 0.84 & & \\
\hline VCF_6 & & & 0.72 & 0.71 & & \\
\hline SP_1 & & & & & 0.90 & 0.90 \\
\hline SP_2 & & & & & 0.92 & 0.88 \\
\hline SP_3 & & & & & 0.90 & 0.94 \\
\hline SP_4 & & & & & 0.88 & 0.80 \\
\hline SP_5 & & & & & 0.88 & 0.81 \\
\hline
\end{tabular}

Furthermore, we evaluated the internal consistency reliability of our measurement constructs. While Cronbach's alpha (CA) and composite reliability (CR) are commonly applied criteria for the evaluation of reflective measurement constructs, prior scholars suggest to prefer 
CR over CA when using PLS-SEM (Chin, 2010; Hair et al., 2012). The limitation of CA is grounded in its bias against short measurements scales and the assumption that all indicators are equally reliable (; Hair et al., 2011). Thus, we specifically emphasize to consider these limitations when interpreting CA estimates using PLS-SEM. For adequate internal consistency reliability, values of 0.70 or higher are suggested for both CA and CR (Nunnally, 1978). As shown in Table 2, all measurement constructs exceed the suggested threshold of 0.70 and, hence, indicate sufficient internal consistency reliability. However, as Dijkstra and Henseler (2015a, p. 3) state, "Cronbach's coefficient alpha (Cronbach 1951) and composite reliability (Chin 2010), are not consistent themselves". Since CA tend to underestimate and CR tend to overestimate the actual reliability of construct scores, the authors recommend to refrain from using CA and CR when estimating models with PLSc (Dijkstra and Henseler, 2015a). Instead, researchers should evaluate and report construct reliability by means of the Dijkstra-Henseler's rho $\left(\mathrm{p}_{\mathrm{A}}\right)$ reliability coefficient (Dijkstra and Henseler, 2015a). ${ }^{1}$ Similar to CA and CR, the reliability coefficient $\rho_{\mathrm{A}}$ should indicate values of 0.70 or higher in exploratory research and values above 0.80 or 0.90 for more advanced stages of research (Hair et al., 2011; Henseler et al., 2009; Nunnally and Bernstein, 1994). As shown in Table 2, the reliability coefficient $\rho_{A}$ of each measurement construct is above 0.70 .

Convergent validity was evaluated by means of the average variance extracted (AVE). Prior literature suggests an AVE value of 0.50 or higher (Hair et al., 2011; Henseler et al., 2009). The estimation with both conventional PLS and PLSc reveal satisfactory AVE values with regard to all measurement constructs (see Table 2). The comparison of both estimation techniques eventually shows that the AVEs deriving from PLSc are slightly below those deriving from traditional PLS. Moreover, we assessed the outer model by means of discriminant validity. Here, we firstly referred to the Fornell-Larcker criterion, which "postulates that latent variable shares more variance with its assigned indicators with another latent variable in the structural model" (Hair et al., 2011, p. 146). In order to fulfill this criterion, the square root of each AVE should be greater than its correlation coefficients with any other latent construct. The Fornell-Larcker criterion is fulfilled with regard to all measures (see Table 2). Secondly, we assessed discriminant validity on the indicator level. To this end, we referred to the crossloadings and evaluated whether each indicator loading with its associated construct exceeds is loading with each of the other constructs (Hair, Ringle, and Sarstedt, 2011; Henseler, Ringle, and Sinkovics, 2009). As shown in Appendix B, this criterion is fulfilled with regard to all measurement items. ${ }^{2}$ Thirdly, we drew upon the recent literature (Henseler, Ringle, and Sarstedt, 2015) and assessed discriminant validity by means of the heterotrait-monotrait ratio (HTMT). While some scholars propose a threshold of 0.90 (e.g., Teo et al., 2008), others recommend values of HTMT that are below 0.85 in order to ensure discriminant validity (Clark and Watson, 1995; Kline, 2011). The HTMT values and the corresponding confidence intervals deriving from a bootstrapping procedure with 500 resamples are outlined in Table $3{ }^{3}$ Since none of our measurement constructs violates the $\mathrm{HTMT}_{0.90}$ and $\mathrm{HTMT}_{0.85}$ criterion and all constructs additionally fulfill the $\mathrm{HTMT}_{\text {inference }}$ test, we infer adequate discriminant validity (Henseler, Ringle, and Sarstedt, 2015).

\footnotetext{
${ }^{1}$ For a more detailed description of the new consistent reliability coefficient $\rho_{\mathrm{A}}$, please refer to Dijkstra and Henseler, 2015a). 2 The indicator loadings indicated in Appendix B derive from the conventional iterative PLS algorithm. Since the existing software packages (e.g., SmartPLS 3.0 or Adanco 1.0) do correct the indicators' cross-loadings with other constructs, discriminant validity on the indicator level was not evaluated with regard to the model estimation using PLSc.

${ }^{3}$ The calculation of HTMT is based on the correlations of individual indicators (Henseler et al., 2015). Since the estimation with PLS and PLSc leads to the same item correlation matrix, the values of HTMT do not differ with regard to PLS and PLSc. Hence, the HTMT values and their corresponding confidence intervals presented in Table 3 relate to the model estimation with both PLS and PLSc
} 
Table 2. Properties of measurement scales and correlations

\begin{tabular}{lccccccccccc}
\hline & ME & SD & $\mathbf{C A}$ & $\mathbf{C R}\left(\mathbf{p}_{\mathbf{c}}\right)$ & $\mathbf{p}_{\mathbf{A}}$ & $\mathbf{A V E}$ & $\mathbf{1}$ & $\mathbf{2}$ & $\mathbf{3}$ & $\mathbf{4}$ & $\mathbf{5}$ \\
\hline 1. Strategic Flexibility & 4.45 & 1.20 & $0.87(/)$ & $0.91(/)$ & $/(0.91)$ & $0.66(0.58)$ & $\mathbf{0 . 8 1}(\mathbf{0 . 7 6})^{\mathrm{a}}$ & & & & \\
2. Value Chain Flexibility & 4.54 & 1.33 & $0.89(/)$ & $0.92(/)$ & $/(0.90)$ & $0.65(0.58)$ & $0.47(0.52)$ & $\mathbf{0 . 8 1}(\mathbf{0 . 7 6})^{\mathrm{a}}$ & & \\
3. Sustainability Performance & 4.38 & 1.49 & $0.94(/)$ & $0.95(/)$ & $/(0.94)$ & $0.80(0.75)$ & $0.21(0.23)$ & $0.47(0.51)$ & $\mathbf{0 . 8 9}(\mathbf{0 . 8 7 7})^{\mathrm{a}}$ & - \\
4. Firm Age & 86.10 & 53.68 & $-(-)$ & $-(-)$ & $-(-)$ & $-(-)$ & $0.10(0.11)$ & $0.09(0.09)$ & $0.36(0.37)$ & - \\
5. Firm Size & 4.53 & 1.24 & $-(-)$ & $-(-)$ & $-(-)$ & $-(-)$ & $-0.03(-0.03)$ & $0.01(0.01)$ & $0.17(0.17)$ & $0.63(0.63)$ & - \\
Note: $\mathbf{M E}=$ Mean. SD $=$ Standard Deviation. CR $=$ Composite Reliability. CA $=$ Cronbach's Alpha. $\mathbf{p}_{\mathbf{A}}=$ Dijkstra-Henseler's rho. AVE $=$ Average Variance \\
Extracted. ${ }^{a}$ Value on the diagonal is the square root of AVE. Values indicated as follows: PLS (PLSc).
\end{tabular}

Table 3. Heterotrait-monotrait ratio (HTMT)

\begin{tabular}{|c|c|c|c|c|c|c|c|c|c|c|c|c|}
\hline & \multicolumn{3}{|c|}{ Strategic Flexibility } & \multicolumn{3}{|c|}{ Value Chain Flexibility } & \multicolumn{3}{|c|}{$\begin{array}{l}\text { Sustainability } \\
\text { Performance }\end{array}$} & \multicolumn{3}{|c|}{ Firm Age } \\
\hline & \multirow{3}{*}{ HTMT } & \multirow{2}{*}{\multicolumn{2}{|c|}{$\begin{array}{l}\text { Confidence } \\
\text { Interval }\end{array}$}} & \multirow{3}{*}{ HTMT } & \multirow{2}{*}{\multicolumn{2}{|c|}{$\begin{array}{c}\text { Confidence } \\
\text { Interval }\end{array}$}} & \multirow{3}{*}{ HTMT } & \multirow{2}{*}{\multicolumn{2}{|c|}{$\begin{array}{c}\text { Confidence } \\
\text { Interval }\end{array}$}} & \multirow{3}{*}{ HTMT } & \multirow{2}{*}{\multicolumn{2}{|c|}{$\begin{array}{l}\text { Confidence } \\
\text { Interval }\end{array}$}} \\
\hline & & & & & & & & & & & & \\
\hline & & Low & Up & & Low & Up & & Low & Up & & Low & Up \\
\hline Value Chain Flexibility & 0.51 & 0.31 & 0.69 & & & & & & & & & \\
\hline Sustainability Performance & 0.23 & 0.00 & 0.44 & 0.50 & 0.28 & 0.69 & & & & & & \\
\hline Firm Age & 0.11 & -0.12 & 0.32 & 0.09 & -0.14 & 0.30 & 0.37 & 0.15 & 0.55 & & & \\
\hline Firm Size & -0.04 & -0.25 & 0.21 & 0.01 & -0.19 & 0.21 & 0.17 & -0.11 & 0.42 & 0.63 & 0.51 & 0.73 \\
\hline
\end{tabular}

\subsection{Results}

While the path coefficients were estimated with the path method (Chin, 2001), their corresponding standard errors have been estimated by performing a bootstrapping procedure with replacement, using 500 resamples (Chin, 1998; Nevitt and Hancock, 1998). Figure 1 and Table 4 entail the results we obtained using both PLS and PLSc.

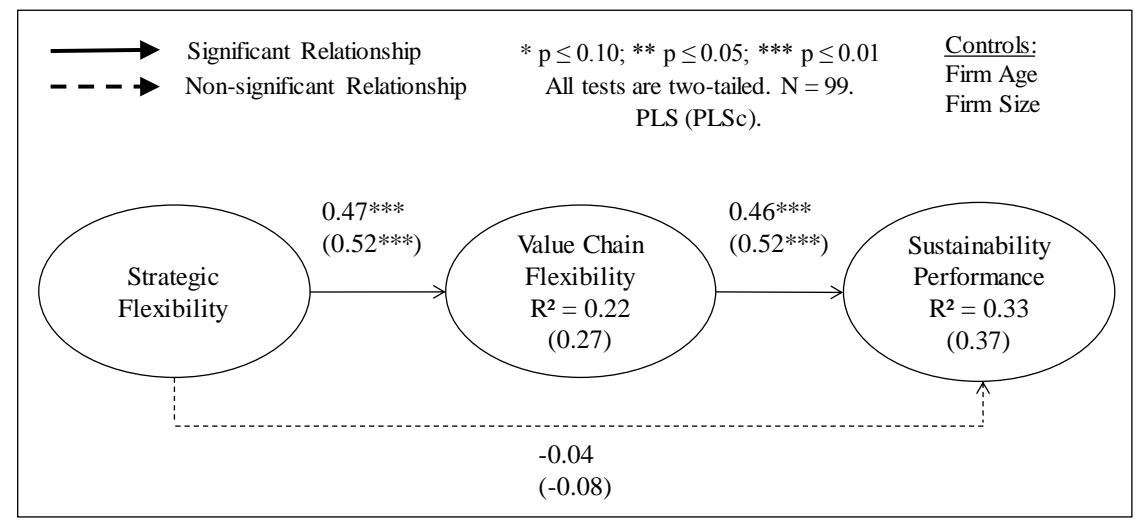

Figure 1. Results of structural equation modeling with PLS and PLSc

Table 4. Results of structural equation modeling with PLS and PLSc

\begin{tabular}{|c|c|c|c|c|}
\hline & \multicolumn{2}{|c|}{ Value Chain Flexibility } & \multicolumn{2}{|c|}{ Sustainability Performance } \\
\hline & $\beta$-value & $\mathrm{p}$-value & $\beta$-value & $\mathrm{p}$-value \\
\hline \multicolumn{5}{|l|}{ Controls } \\
\hline Firm Age & $0.04(0.03)$ & $0.75(0.83)$ & $0.37(0.38)$ & $<0.001(<0.001)$ \\
\hline Firm Size & $0.00(0.01)$ & $0.99(0.96)$ & $-0.07(-0.07)$ & $0.62(0.61)$ \\
\hline \multicolumn{5}{|l|}{ Main Effects } \\
\hline Strategic Flexibility & $0.47(0.52)$ & $<0.001(<0.001)$ & $-0.04(-0.08)$ & $0.71(0.53)$ \\
\hline Value Chain Flexibility & & & $0.46(0.52)$ & $<0.001(<0.001)$ \\
\hline$\underline{\text { R-Square }}$ & \multicolumn{2}{|c|}{$0.22(0.27)$} & \multicolumn{2}{|c|}{$0.33(0.37)$} \\
\hline
\end{tabular}

\subsection{Mediation Analysis}

To further define the degree of the mediating effect of value chain flexibility within the strategic flexibility-sustainability performance relationship, we followed Subramani (2004) and compared two competing models: (i) a full mediation model (research model) and (ii) a partially 
mediated model (nested model). We specifically assessed whether the incorporation of a direct path substantively improves the explanation of the dependent variable. As shown in Table 5, value chain flexibility fully mediates the relationships between strategic flexibility and sustainability performance with regard to the estimation with both PLS $\left(f^{2}=0.001 ; p=0.708\right)$ and PLSc $\left(\mathrm{f}^{2}=0.003 ; \mathrm{p}=0.584\right){ }^{4}$

Table 5. Nested-model comparison

\begin{tabular}{lcccccc}
\hline Estimation Method & $\begin{array}{c}\mathrm{R}^{2} \text { in Nested } \\
\text { Model }\end{array}$ & $\begin{array}{c}\mathrm{R}^{2} \text { in Full } \\
\text { model }\end{array}$ & $\begin{array}{c}\text { Magnitude of } \\
\text { the change }\left(\mathrm{f}^{2}\right)\end{array}$ & Pseudo F & $\mathrm{p}$-value & Conclusion $^{\mathrm{a}}$ \\
\hline PLS & 0.325 & 0.326 & 0.001 & 0.141 & 0.708 & Full mediation \\
PLSc & 0.368 & 0.370 & 0.003 & 0.302 & 0.584 & Full mediation \\
\hline a Significance level: $\mathrm{p} \leq 0.05$. & & & & & \\
\hline
\end{tabular}

\subsection{Model Fit and Prediction Analysis ${ }^{5}$}

To assess the prediction power of our proposed research model, we referred to the explained variance $\left(\mathrm{R}^{2}\right)$ of all dependent variables. Since our results indicate a $\mathrm{R}^{2}$ value of 0.22 (0.27) for value chain flexibility and 0.33 (0.37) for sustainability performance, our proposed research models shows weak to moderate prediction power (Chin, 1998). We also evaluated the effect size of the predictor constructs by computing their corresponding Cohen's $\mathrm{f}^{2}$ values (Cohen, 1988; Henseler et al., 2009). Cohen's $\mathrm{f}^{2}$ values are represented in Table 6. As rule of thumb, prior scholars (Cohen, 1988; Chin, 1998) recommend Cohen's $\mathrm{f}^{2}$ values of 0.02, 0.15, and 0.35 for small, medium, and large effect size. Furthermore, we evaluate the prediction relevance of our proposed research model by means of a non-parametric Stone-Geisser test. The Stone-Geisser $Q^{2}$ values derive from a blindfolding procedure with an omission distance of 5 and were calculated by means of the cross-validated redundancy approach (Hair et al., 2012). Since all values are greater than zero, we infer that all endogenous constructs show adequate predictive relevance (see Table 6) (Götz et al., 2010; Henseler et al., 2009). Table 6 further indicates the relative prediction relevance $\left(q^{2}\right)$ of each predictor variable for the endogenous constructs of our proposed research model. The effect of strategic flexibility on value chain flexibility $\left(q^{2}=0.159\right)$ and the effect of value chain flexibility on sustainability $\left(q^{2}\right.$ $=0.179$ ) both show small to medium prediction relevance. ${ }^{6}$

Table 6. Effect size (Cohen's $\left.\mathrm{f}^{2}\right)$ and relative prediction relevance $\left(q^{2}\right)$

\begin{tabular}{lcccccc}
\hline & \multicolumn{3}{c}{ Effect size } & \multicolumn{3}{c}{ Relative prediction relevance } \\
\multicolumn{1}{c}{ Path } & $\mathrm{R}_{\text {incl }}^{2}$ & $\mathrm{R}_{\text {excl }}^{2}$ & Cohen's f & $\mathrm{Q}_{\text {incl }}^{2}$ & $\mathrm{Q}_{\text {excl }}^{2}$ & $\mathrm{q}^{2}$ \\
\hline $\begin{array}{l}\text { Strategic Flexibility - } \\
\begin{array}{l}\text { Value Chain Flexibility } \\
\text { Strategic Flexibility - }\end{array}\end{array}$ & $0.223(0.273)$ & $0.011(0.012)$ & $0.273(0.359)$ & $0.140(/)$ & $0.003(/)$ & $0.159(/)$ \\
$\begin{array}{l}\text { Sustainability Performance } \\
\begin{array}{l}\text { Value Chain Flexibility - } \\
\text { Sustainability Performance }\end{array}\end{array}$ & $0.326(0.373)$ & $0.325(0.368)$ & $0.001(0.008)$ & $0.255(/)$ & $0.255(/)$ & $0.000(/)$ \\
\hline Values presented as follows: PLS (PLSc). & $0.326(0.373)$ & $0.166(0.178)$ & $0.237(0.311)$ & $0.255(/)$ & $0.122(/)$ & $0.179(/)$ \\
\hline
\end{tabular}

In contrast to CB techniques for SEM, PLS lacks a global goodness-of-fit measure. To overcome this shortcoming, prior scholars (e.g., Vinzi et al., 2010; Tenenhaus et al., 2005) suggest the use of the goodness-of-fit' (GoF) criterion, which can be understood as the geometric mean of the average communality and average explained variance. Both model estimation with PLS reveal a GoF that exceeds the suggested threshold of 0.36 for large effect

\footnotetext{
${ }^{4}$ Moreover, we evaluated the magnitude and significance of the indirect path between strategic flexibility and sustainability performance via value chain flexibility. For both estimation techniques, i.e., PLS $(\beta=0.21, \mathrm{p}<0.001)$ and PLSc $(\beta=0.21, \mathrm{p}$ $<0.001$ ), the indirect path is positive and significant.

${ }^{5}$ Values presented as follows: PLS (PLSc).

${ }^{6}$ Since PLSc does not impact the consistency of the predictive relevance of the research model, we solely performed the blindfolding procedure for the model estimation with PLS.
} 
sizes of R ${ }^{2}$ (PLS: 0.44; PLSc: 0.45). However, more recent literature particularly shows that the measure is not suitable for model validation (Henseler and Sarstedt, 2013). Hair et al. (2014), therefore, recommend evaluating the model's overall quality in terms of how well it predicts the endogenous constructs. Considering the inadequacy of $\mathrm{GoF}$ as global goodness-of-fit measure, we followed Henseler et al. (2014) and additionally referred to the standardized root mean square residual (SRMR) as index for model validation. The absolute measure of model fit is defined as the difference between the observed correlation and the predicted correlation. Values below 0.08 are generally considered as favorable (Hu and Bentler, 1999). While the model estimation with PLS (composite factor model) reveals a SRMR value of 0.075, the estimation with PLSc (common factor model) indicates a SRMR value of 0.164.

\section{Discussion and Implications}

Product innovations that transform the nature of production and consumption, an increasingly interconnected global economy that is altering social conditions, and an environment that is more unpredictable than ever before, have prompted sustainability as an important business issue on the agenda of many managers and force them to question existing assumptions of how to create value (Kiron et al., 2013). As Nidumolu et al. argue, "the quest for sustainability is already starting to transform the competitive landscape, which will force companies to change the way they think about products, technologies, processes, and business models" (2009: 58). Considering sustainability as an important business issue, our study underlines the critical role of flexibility in both strategic and operational actions in achieving high sustainability performance. Stimulated by strategic flexibility, value chain flexibility enables firms to deliver sustainable products and services in a timely manner, cope with changing customer requirements, shorten lead times and reduce inventory costs (Zhang et al., 2002). Apart from contributing to the ongoing debate on the triple bottom line within the management literature, these findings contribute to the dynamic-resource based view of the firm (e.g., Helfat and Peteraf, 2003; Teece, 1997). The results of our empirical analysis demonstrate that an operational capability, here value chain flexibility, fully mediates the relationship between a dynamic capability, here strategic flexibility, and sustainability-related performance outcomes. Hence, our empirical findings reveal strategic flexibility and value chain flexibility as distinct yet interlinked capabilities in the pursuit of superior sustainability performance. By this means, we empirically support Helfat and Peteraf, who argue that "[d]ynamic capabilities do not directly affect output for the firm in which they reside, but indirectly contribute to the output of the firm through an impact on operational capabilities" (2003, p. 999).

Furthermore, we contribute to the ongoing research on the PLS approach to SEM by estimating our proposed research model using both conventional PLS and consistent PLS. The comparison of both estimation methods reveals the typical pattern of results with regard to traditional PLS: While the outer loadings were overestimated, the inter-construct correlations were attenuated (Dijkstra and Henseler, 2015b). Considering the high values of the reliability coefficient $\rho_{\mathrm{A}}$, the subsequent correction undertaken by PLSc however was rather weak, causing merely small differences the estimates deriving from PLS and PLSc. Both estimation methods eventually lead to the same conclusion: value chain flexibility fully mediates the relationship between strategic flexibility and sustainability performance.

\section{References}

Armstrong, J. S., \& Overton, T. S. (1977). Estimating nonresponse bias in mail surveys. Journal of Marketing Research 14, 396-402.

Bahrami, H., \& Evans, S. (2000). Flexible recycling and high-technology entrepreneurship. 
Understanding Silicon Valley: The Anatomy of an Entrepreneurial Region, 165-189.

Berns, M., Townend, A., Khayat, Z., Balagopal, B., Reeves, M., Hopkins, M.S., and Kruschwitz, N. "The business of sustainability: what it means to managers now." MIT Sloan Management Review 51(2009), 20-26.

Bock, A. J., Opsahl, T., George, G., \& Gann, D. M. (2012). The effects of culture and structure on strategic flexibility during business model innovation. Journal of Management Studies, 49(2), 279-305.

Chin, W. W. 1998. The partial least squares approach to structural equation modeling. In Modern Methods for Business Research, ed. G.A. Marcoulides, 295-336. Mahwah: Lawrence Erlbaum Associates.

Chin, W.W. 2001. PLS-Graph user's guide. Available at: http://carma.wayne.edu/documents/oct1405/plsgraph3.0manual.hubona.pdf [11/10/2013].

Chin, W. W. (2010). How to write up and report PLS analyses. In Handbook of Partial Least Squares (pp. 655-690). Springer Berlin Heidelberg.

Chin, W. W., \& Newsted, P. R. (1999). Structural equation modeling analysis with small samples using partial least squares. In Statistical Strategies for Small Sample Research, ed. R.H. Hoyle, 307-341. Thousand Oaks: Sage Publications.

Chin, W. W., Marcolin, B. L., \& Newsted, P. R. (2003). A partial least squares latent variable modeling approach for measuring interaction effects: Results from a Monte Carlo simulation study and an electronic-mail emotion/adoption study. Information Systems Research, 14(2), 189-217.

Chow, W. S., \& Chen, Y. (2012). Corporate sustainable development: Testing a new scale based on the mainland Chinese context. Journal of Business Ethics, 105(4), 519-533.

Clark, L. A., \& Watson, D. (1995). Constructing validity: Basic issues in objective scale development. Psychological Assessment, 7(3), 309.

Cohen, J. (1988). Statistical Power Analysis for the Behavioral Sciences, 2nd ed. Hillside: Lawrence Erlbaum Associates.

Composite Modeling. (2014). Kleve: Composite Modeling GmbH \& Co. KG, http://www.composite-modeling.com/

Dijkstra, T. K., \& Henseler, J. (2015a). Consistent and asymptotically normal PLS estimators for linear structural equations. Computational Statistics \& Data Analysis, 81, 10-23.

Dijkstra, T. K., \& Henseler, J. (2015b). Consistent partial least squares path modeling. MIS Quarterly (in press).

Eisenhardt, K. M., \& Martin, J. A. (2000). Dynamic capabilities: What are they? Strategic Management Journal, 21(1), 1105-1121.

Eisenhardt, K. M., Furr, N. R., \& Bingham, C. B. (2010). CROSSROADS-Microfoundations of Performance: Balancing Efficiency and Flexibility in Dynamic Environments. Organization Science, 21(6), 1263-1273.

Eisenhardt, K. M. (1989). Making fast strategic decisions in high-velocity environments. Academy of Management Journal, 32(3), 543-576.

Gefen, D., Straub, D. W., \& Rigdon, E. E. (2011). An update and extension to SEM guidelines for admnistrative and social science research. MIS Quarterly, 35(2), iii-xiv.

Götz, O., Liehr-Gobbers, K., \& Krafft, M. (2010). Evaluation of structural equation models using the partial least squares (PLS) approach. In Handbook of Partial Least Squares (pp. 691-711). Springer Berlin Heidelberg.

Grewal, R., \& Tansuhaj, P. (2001). Building organizational capabilities for managing economic crisis: The role of market orientation and strategic flexibility. Journal of Marketing, 65(2), 67-80.

Hair, J. F., Ringle, C. M., \& Sarstedt, M. (2011). PLS-SEM: Indeed a silver bullet. The Journal 
of Marketing Theory and Practice, 19(2), 139-152.

Hair, J. F., Sarstedt, M., Ringle, C. M., \& Mena, J. A. (2012). An assessment of the use of partial least squares structural equation modeling in marketing research. Journal of the Academy of Marketing Science, 40(3), 414-433.

Hart, S.L. "A natural-resource-based view of the firm." Academy of Management Review 20, no. 4 (1995), 986-1014.

Helfat, C. E., \& Peteraf, M. A. (2003). The dynamic resource-based view: Capability lifecycles. Strategic Management Journal, 24(10), 997-1010.

Henseler, J., \& Chin, W. W. (2010). A comparison of approaches for the analysis of interaction effects between latent variables using partial least squares path modeling. Structural Equation Modeling, 17(1), 82-109.

Henseler, J., \& Sarstedt, M. (2013). Goodness-of-fit indices for partial least squares path modeling. Computational Statistics, 28(2), 565-580.

Henseler, J., C.M. Ringle, \& R.R. Sinkovics. (2009). The use of partial least squares path modeling in international marketing. Advances in International Marketing 20(1), $277-$ 319.

Henseler, J., Dijkstra, T. K., Sarstedt, M., Ringle, C. M., Diamantopoulos, A., Straub, D. W., Ketchen, D. J., Hair, J. F., Hult, G.T.M., \& Calantone, R. J. (2014). Common Beliefs and Reality About PLS Comments on Rönkkö and Evermann (2013). Organizational Research Methods 17(2), 182-209.

Henseler, J., Ringle, C. M., \& Sarstedt, M. (2015). A new criterion for assessing discriminant validity in variance-based structural equation modeling. Journal of the Academy of Marketing Science 43(1), 115-135.

Hu, L. T., \& Bentler, P. M. (1999). Cutoff criteria for fit indexes in covariance structure analysis: Conventional criteria versus new alternatives. Structural Equation Modeling: A Multidisciplinary Journal, 6(1), 1-55.

Hulland, J. (1999). Use of partial least squares (PLS) in strategic management research: A review of four recent studies. Strategic Management Journal, 20(2), 195-204.

Jenck, J.F., Agterberg, F., \& Droescher, M.J. (2004). Products and processes for a sustainable chemical industry: a review of achievements and prospects. Green Chemistry 6(11), 544-556.

Joshi, M. P., Kathuria, R., \& Porth, S. J. (2003). Alignment of strategic priorities and performance: an integration of operations and strategic management perspectives. Journal of Operations Management, 21(3), 353-369.

Kiron, D., Kruschwitz, N., Rubel, H., Reeves, M., and Fuisz-Kehrbach, S.-K. (2013). Sustainability's Next Frontier - Walking the Talk on the Sustainability Issues That Matter Most. http://sloanreview.mit.edu/projects/sustainabilitys-next-frontier/, accessed March 2013.

Kline, R.B. 1998. Principles and practice of structural equation modeling. New York: The Guilford Press.

Kolk, A., \& Pinkse, J. (2005). Business responses to climate change: identifying emergent strategies. California Management Review 47, no. 3 (2005), 6-20.

Kortmann, S., Gelhard, C., Zimmermann, C., \& Piller, F. T. (2014). Linking strategic flexibility and operational efficiency: The mediating role of ambidextrous operational capabilities. Journal of Operations Management, 32(7), 475-490.

Li, T., \& Calantone, R. J. (1998). The impact of market knowledge competence on new product advantage: conceptualization and empirical examination. The Journal of Marketing, 1329.

Liang, H., Saraf, N., Hu, Q., \& Xue, Y. (2007). Assimilation of enterprise systems: the effect of institutional pressures and the mediating role of top management. MIS Quarterly, 59- 
87.

Milgrom, P., \& Roberts, J. (1995). Complementarities and fit strategy, structure, and organizational change in manufacturing. Journal of Accounting and Economics, 19(2), 179-208.

Nadkarni, S., \& Narayanan, V. K. (2007). Strategic schemas, strategic flexibility, and firm performance: the moderating role of industry clockspeed. Strategic Management Journal, 28(3), 243-270.

Nair, A. (2005). Linking manufacturing postponement, centralized distribution and value chain flexibility with performance. International Journal of Production Research, 43(3), 447463.

Nevitt, J., \& Hancock, G. R. (2000). Improving the root mean square error of approximation for nonnormal conditions in structural equation modeling. The Journal of Experimental Education, 68(3), 251-268.

Nidumolu, R., Prahalad, C.K., and Rangaswami, M.R. (2009) Why sustainability is now the key driver of innovation, Harvard Business Review 87, no. 9 (2009), 56-64.

Nunnally, J. (1978). Psychometric Theory. McGraw Hill: New York, NY.

Nunnally, I.C \& Bernstein, I. (1994). Psychometric theory. McGraw-Hill: New York, NY.

Park, S. H., \& Luo, Y. (2001). Guanxi and organizational dynamics: Organizational networking in Chinese firms. Strategic Management Journal, 22(5), 455-477.

Peng, D. X., \& Lai, F. (2012). Using partial least squares in operations management research: A practical guideline and summary of past research. Journal of Operations Management, 30(6), 467-480.

Podsakoff, P. M., MacKenzie, S. B., Lee, J. Y., \& Podsakoff, N. P. (2003). Common method biases in behavioral research: a critical review of the literature and recommended remedies. Journal of Applied Psychology, 88(5), 879-903.

Ringle CM, Wende S, Becker J.M. (2015). SmartPLS 3. Boenningstedt: SmartPLS GmbH, http://www.smartpls.com.

Shimizu, K., \& Hitt, M. A. (2004). Strategic flexibility: Organizational preparedness to reverse ineffective strategic decisions. Academy of Management Executive, 18(4), 44-59.

Subramani, M. (2004). How do suppliers benefit from information technology use in supply chain relationships? MIS Quarterly 28(1), 45-73.

Teece, D.J., Pisano, G., \& Shuen, A. (1997). Dynamic capabilities and strategic management. Strategic Management Journal 18(7), 509-533.

Tenenhaus, M., Vinzi, V. E., Chatelin, Y. M., \& Lauro, C. (2005). PLS path modeling. Computational Statistics \& Data Analysis, 48(1), 159-205.

Teo, T. S., Srivastava, S. C., \& Jiang, L. (2008). Trust and electronic government success: An empirical study. Journal of Management Information Systems, 25(3), 99-132.

Vinzi, V. E., Chin, W. W., Henseler, J., \& Wang, H. (2010). Editorial: Perspectives on partial least squares (pp. 1-20). Springer Berlin Heidelberg.

Young-Ybarra, C., \& Wiersema, M. (1999). Strategic flexibility in information technology alliances: The influence of transaction cost economics and social exchange theory. Organization Science, 10(4), 439-459.

Zhang, Q., Vonderembse, M. A., \& Lim, J. S. (2002). Value chain flexibility: a dichotomy of competence and capability. International Journal of Production Research, 40(3), 561583.

Zhang, Q., Vonderembse, M. A., \& Lim, J. S. (2003). Manufacturing flexibility: defining and analyzing relationships among competence, capability, and customer satisfaction. Journal of Operations Management, 21(2), 173-191.

Zhou, K. Z., \& Wu, F. (2010). Technological capability, strategic flexibility, and product innovation. Strategic Management Journal, 31(5), 547-561. 


\section{Appendix A: Descriptive Statistics}

\begin{tabular}{lc|lc}
\hline Key Informant Descriptive Statistics & & Firm Descriptive Statistics & \\
\hline Job Title & & \multicolumn{2}{|l}{ Firm Size (Number of Full Time Employees) } \\
\hline CEO & 15 & $1-10$ & 3 \\
CTO & 1 & $11-50$ & 8 \\
Vice President & 1 & $51-250$ & 6 \\
Executive Director & 1 & $251-1000$ & 14 \\
Director & 4 & $1.001-50.000$ & 53 \\
Chairman & 2 & $>50.000$ & 15 \\
\cline { 2 - 2 } Business Unit Manager & 5 & & \\
Head of Department & 21 & Firm Age (in years) & \\
Senior Manager & 2 & & \\
Partner & 1 & & \\
Operations Manager & 6 & & \\
General Manager & 40 & & \\
Involvement in... & AVG (SD) & & \\
... strategic decision making & $5.14(1.72)$ & & \\
$\ldots$ innovation decision making & $5.39(1.52)$ & & \\
$\ldots$ operation decision making & $4.91(1.77)$ & & \\
Organizational tenure (in years) & $12.64(9.87)$ & & \\
Overall work experience (in years) & $19.87(10.23)$ & & \\
Age (in years) & $46.23(11.35)$ & & \\
\hline
\end{tabular}

\section{Appendix B: Measures}

\begin{tabular}{|c|c|c|c|c|c|}
\hline \multicolumn{6}{|l|}{ ategic Fle xibility (Zhou and Wu, 2010) } \\
\hline $\begin{array}{l}\text { SF } 3 \text { The flexibility of product design (such as modular product design) to support a broad range of potential product } \\
\text { applications. }\end{array}$ & 4.39 & 1.53 & 0.74 & 0.25 & 0.10 \\
\hline SF 4 The redefinition of product strategies in terms of target market segments. & 4.70 & 1.47 & 0.91 & 0.48 & 0.21 \\
\hline VCF 1 We have a flexible program of special services that can be matched to $\mathrm{c}$ & 4.29 & 1.70 & 0.41 & 0.75 & 0.28 \\
\hline VCF 2 We have established a program to authorize and perform special requests made by selected customers & 4.89 & 1.65 & 0.40 & 0.78 & 0.26 \\
\hline VCF 3 We are able to accommodate a wide range of unique customer requests by implementing pre-planned solutions. & 4.36 & 1.70 & 0.42 & 0.84 & 0.47 \\
\hline $\begin{array}{l}\text { VCF } 4 \text { We have adequate ability to share both standardized and customized information externally with suppliers and/or } \\
\text { customers. }\end{array}$ & 4.54 & 1.66 & 0.36 & 0.90 & 0.39 \\
\hline VCF 5 We have adequate ability to share both standardized and customized information internally. & 4.87 & 1.57 & 0.34 & 0.84 & 0.49 \\
\hline $\begin{array}{l}\text { SP } 3 \text { We develop new products/services or improve existing products/services that are regarded as sustainable for society and } \\
\text { environment. }\end{array}$ & 4.59 & 1.79 & 0.20 & 0.41 & 0.90 \\
\hline SP 4 Our reputation in terms of sustainability is better than the sustainability reputation of our competitors. & 4.48 & 1.68 & 0.16 & 0.40 & 0.88 \\
\hline SP 5 Compared to our competitors, we more thoroughly respond to societal and ethical demands & 4.37 & 1.55 & 0.21 & 0.42 & 0.88 \\
\hline
\end{tabular}

